\title{
The Effect of Polarisation on the Electrochemical Behavior of Ti-13Nb-13Zr Alloy
}

\author{
Sérgio Luiz de Assis, Isolda Costa* \\ Materials Science and Technology Centre, IPEN/CNEN-SP, \\ Av. Prof. Lineu Prestes, 2242, 05508-900 São Paulo, SP, Brazil
}

Received: March 16, 2007; Revised: June 22, 2007

\begin{abstract}
The effect of potentiostatic polarisation on the electrochemical behavior of the Ti-13Nb-13Zr alloy was investigated by electrochemical impedance spectroscopy (EIS) and potentiodynamic polarisation curves in Hanks' solution at $37^{\circ} \mathrm{C}$. Potentiodynamic polarisation curves show a passive behavior with a slight current increase as potentials around $1300 \mathrm{mV}(\mathrm{SCE})$. Based on these curves, different potentials were chosen to perform potentiostatic EIS experiments. EIS experimental data were interpreted using different equivalent circuits associated with the duplex nature of the oxide layer. The fitting procedure evidenced the thickening of a defective oxide layer with the applied potentials, corresponding to key points in the potentiodynamic polarisation curves.
\end{abstract}

Keywords: passive films, Ti-13Nb-13Zr, biomaterials, EIS

\section{Introduction}

Titanium alloys are very resistant to corrosion due to the highly protective oxide film, mainly composed of $\mathrm{TiO}_{2}$ that covers the metallic substrate. This oxide film is spontaneously formed on the Ti alloy surface when exposed to the atmosphere, and its thickness is initially approximately $1.4 \mathrm{~nm}$, but it can reach $5 \mathrm{~nm}$ after 70 days, 8 to $9 \mathrm{~nm}$ after 545 days and $25 \mathrm{~nm}$ after 4 years of atmospheric exposure $^{1}$. When the film is damaged, resulting in the exposure of the metallic substrate, it is rapidly repaired in the presence of even traces of oxygen or humidity. Due to their high corrosion resistance associated to good mechanical properties and high strength-to-weight ratio, these alloys find wide applications, among them as biomaterials for implant fabrication.

The corrosion behavior and oxide properties characterisation of $\mathrm{Ti}$ and its alloys have been largely investigated and, in many of these studies, electrochemical methods, such as EIS and polarisation methods, have been used. Zhu Cai et al., investigated the electrochemical behavior of titanium and titanium alloys with various surface finishing in acid lactic/ $\mathrm{NaCl}$ solution and modified Fusayama artificial saliva and the results showed an extensive passive region for these materials from the corrosion potential until approximately $1600 \mathrm{mV}$ $(\mathrm{Ag} / \mathrm{AgCl}) . \mathrm{A}$ large increase in current density occurred for potentials higher than this last potential, and the authors related it to the oxide film breakdown. However, at higher potentials, a decrease in current density was indicated in the polarisation curves, and these authors attributed it to repassivation.

Kolman and Scully ${ }^{4,5}$ studied the passivity behavior of $\beta$-type titanium alloys in chloride solutions and also observed an increase in current density at potentials of approximately $1600 \mathrm{mV}$ (SCE). Oppositely to Zhu Cai et al., Kolman and Scully attributed the current increase to the oxygen evolution reaction. They used optical microscopy to investigate the alloy surface after polarisation but pits were not found on it. According to these authors, pitting does not occur on these alloys until polarisation potentials of the order of $9 \mathrm{~V}$. Kolman and Scully attributed the decrease in current density at potentials of approximately $1900 \mathrm{mV}$ (SCE) to the decrease in the rate of the oxygen evolution reaction caused by the hindering of charge transfer through the growing oxide film. This was also observed for other Ti alloys, at different potentials. Other researchers ${ }^{6}$ have also observed this current density increase around this potential, at even larger rates, when the polarisation curves were obtained in more complex solutions, such as a MEM culture medium ${ }^{7}$, however, there is no general agreement on what causes this current increase followed by its drop, in this potential range. The aim of this study was to evaluate the effect of potentiodynamic polarisation on the electrochemical behavior of Ti-13Nb-13Zr alloy using polarisation curves and electrochemical impedance spectroscopy (EIS), besides of investigate the causes of current density variations at around $1300 \mathrm{mV}$ (SCE).

\section{Materials and Methods}

The near- $\beta$ Ti-13Nb-13Zr alloy used in this study was laboratory prepared by $\mathrm{Schneider}^{8}$, and its chemical composition determined by inductively coupled plasma - atomic emission spectroscopy (ICPAES) is shown in Table 1. The alloy was obtained by melting pure Ti and $\mathrm{Nb}(99.9 \%)$ and $\mathrm{Zr}$ containing up to $4.5 \%$ of $\mathrm{Hf}$, in an arc melting furnace, using a non consumable electrode, in an argon atmosphere. After melting, the ingot was heat treated for 1 hour at $1000{ }^{\circ} \mathrm{C}$, followed by water-cooling for homogenisation. Subsequently, the alloy was cold worked (forged) to a diameter of $6.5 \mathrm{~mm}$. During the forging stage the alloy was once again heat treated at $1000{ }^{\circ} \mathrm{C}$, followed by water cooling. ${ }^{8}$.

Working electrodes were prepared by cold epoxy resin mounting, leaving an exposed area of $0.33 \mathrm{~cm}^{2}$. The surface was prepared by sequential grinding with silicon carbide paper, followed by mechanical polishing with diamond paste up to $1 \mu \mathrm{m}$. After polishing, the surface was degreased with acetone in an ultrasonic bath for 10 minutes and then rinsed with deionised water. A three-electrode cell arrangement was used for the electrochemical measurements, with a saturated calomel electrode (SCE) as reference and a platinum wire as the auxiliary electrode. The electrolyte used to simulate the physiological medium and to perform the electrochemical tests was a naturally aerated Hanks' solution at $37^{\circ} \mathrm{C}$ which composition is presented in Table 2 . The $\mathrm{pH}$ of this solution is 6.8 , that is very similar to that of physiological fluids. 
Table 1. Chemical composition of Ti-13Nb-13Zr alloy.

\begin{tabular}{cccccccccccc}
\hline Element & $\mathrm{C}$ & $\mathrm{H}$ & $\mathrm{N}$ & $\mathrm{O}$ & $\mathrm{S}$ & $\mathrm{Hf}$ & $\mathrm{Fe}$ & $\mathrm{Nb}$ & $\mathrm{Zr}$ & $\mathrm{Ti}$ \\
\hline$\%$ (mass) & 0.035 & 0.011 & 0.004 & 0.075 & $<0.001$ & 0.055 & 0.085 & 13.18 & 13.49 & $\mathrm{Bal}$ \\
\hline
\end{tabular}

Table 2. Chemical composition of Hanks' solution.

\begin{tabular}{lc}
\hline \multicolumn{1}{c}{ Component } & Concentration $\left(\right.$ Mol.L $\left.^{-1}\right)$ \\
\hline $\mathrm{NaCl}$ & 0.1369 \\
$\mathrm{KCl}$ & 0.0054 \\
$\mathrm{MgSO}_{4} \cdot 7 \mathrm{H}_{2} \mathrm{O}$ & 0.0008 \\
$\mathrm{CaCl}_{2} \cdot 2 \mathrm{H}_{2} \mathrm{O}$ & 0.0013 \\
$\mathrm{Na}_{2} \mathrm{HPO}_{4} \cdot 2 \mathrm{H}_{2} \mathrm{O}$ & 0.0003 \\
$\mathrm{KH}_{2} \mathrm{PO}_{4}$ & 0.0004 \\
$\mathrm{C}_{6} \mathrm{H}_{12} \mathrm{O}_{6} \mathrm{H}_{2} \mathrm{O}$ & 0.0050 \\
$\mathrm{Red} \mathrm{phenol} 1 \%$ & 0.0071 \\
$\mathrm{pH}$ & 6.8 \\
\hline
\end{tabular}

After surface preparation and prior to EIS tests, all the samples remained immersed for 72 hours in the test electrolyte and the open circuit potential was accompanied until a steady state was reached. Afterwards EIS diagrams were sequentially obtained firstly at the open circuit potential (OCP), and then at $500 \mathrm{mV}(\mathrm{SCE})$ and $1300 \mathrm{mV}(\mathrm{SCE})$, in these last two cases a 20 minutes polarisation step was applied prior to the EIS experiments. The EIS data at the various potentials were obtained with only one working electrode.

EIS tests were carried out by means of a Solartron SI-1255 frequency response analyser coupled to a EG\&G PARC 273A potentiostat and controlled by the software Zplot. EIS measurements were performed in potentiostatic mode and the frequency range was from $100 \mathrm{kHz}$ to $10 \mathrm{mHz}$. The amplitude of the perturbation signal was $10 \mathrm{mV}$ with 6 points per decade acquisition rate.

Polarisation was carried out using an EG\&G PARC 273A Potentiostat in the potential range from $-800 \mathrm{mV}$ (SCE) to $3000 \mathrm{mV}$ (SCE) and the scan rate was $1 \mathrm{mV} \cdot \mathrm{s}^{-1}$.

\section{Results and Discussion}

Figure 1 shows a polarisation curve for the Ti-13Nb-13Zr after 72 hours of immersion in Hanks' solution. The current density increased with the polarisation potential from the OCP until approximately $500 \mathrm{mV}(\mathrm{SCE})$. From this last potential until nearly $1300 \mathrm{mV}$ (SCE) the current was fairly constant and in the order of $10^{-6} \mathrm{~A} . \mathrm{cm}^{-2}$, that is typical of a passive behavior. The current increase with potential from OCP to $500 \mathrm{mV}$ (SCE) might be due to the relatively high scan rate used and consequently the thickening of the oxide film being insufficient to compensate the high field effects of the overpotential. At $1300 \mathrm{mV}$ (SCE) the current density increased again but at approximately $1700 \mathrm{mV}(\mathrm{SCE})$ the current density stabilised once more with the potential increase at nearly $14 \mu \mathrm{A} . \mathrm{cm}^{-2}$ until $3 \mathrm{~V}(\mathrm{SCE})$, when the polarisation test was finished.

The Bode diagrams corresponding to the EIS results obtained at OCP, $500 \mathrm{mV}$ (SCE) and $1300 \mathrm{mV}$ (SCE) are shown in Figure 2. The polarisation potentials at which the EIS data were obtained were chosen from the results of the polarisation curves and represent the begin of the first current plateau and the second current increase, respectively. The impedance diagrams obtained at OCP show a highly capacitive behavior from medium to low frequencies with phase angles approaching $-90^{\circ}$, typical of passive materials. For the samples polarised at $500 \mathrm{mV}$ (SCE) however, there is a significant decrease

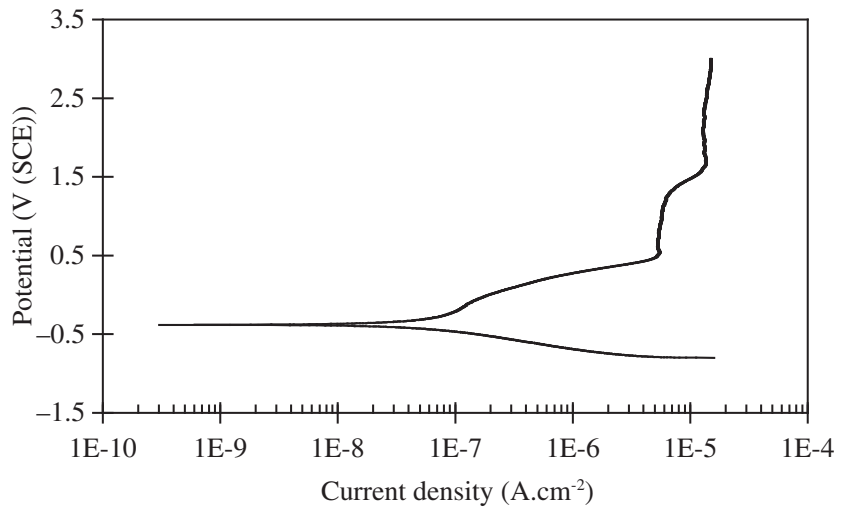

Figure 1. Potentiodynamic polarisation curve for Ti-13Nb-13Zr alloy after 72 hours of immersion in Hanks' naturally aerated solution at $\mathrm{pH} 6.8$ and $37^{\circ} \mathrm{C}$.

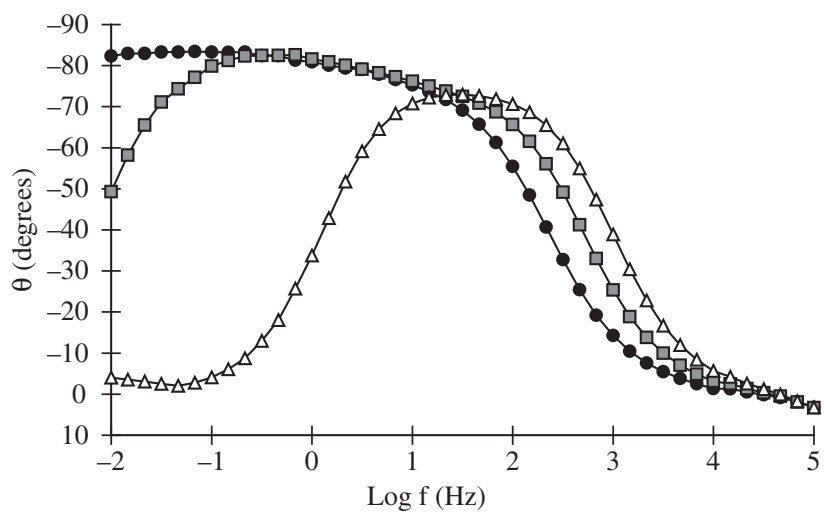

(a)

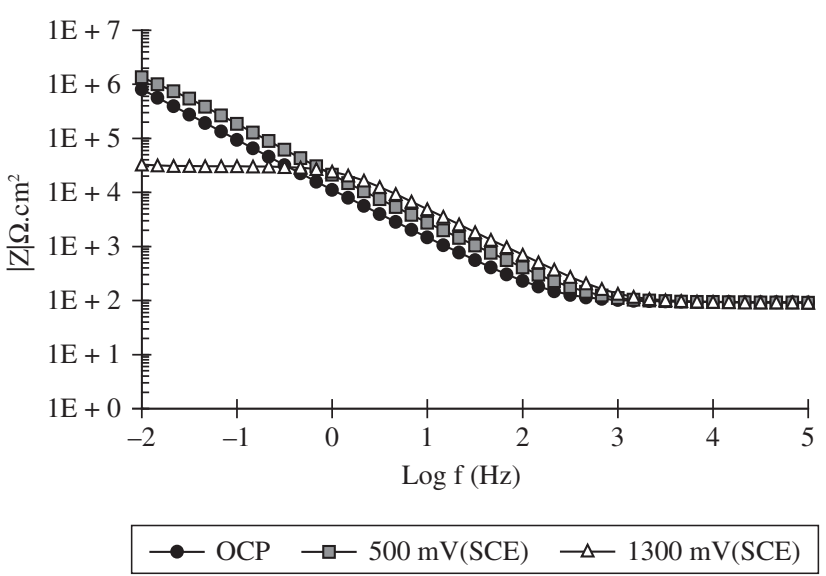

(b)

Figure 2. Bode diagrams for Ti-13Nb-13Zr alloy after 72 hours of immersion in Hanks' solution obtained at OCP, $500 \mathrm{mV}$ (SCE) and $1300 \mathrm{mV}(\mathrm{SCE})$ : a) Phase angle Bode diagram; and b) $\mathrm{Z}$ modulus Bode diagram. 
in the phase angles at low frequencies but they increase at medium frequencies. The results at low frequencies suggest the deterioration of the protective properties of the passive film whereas that at high frequencies might indicate the oxide film thickening. The EIS data obtained for the specimens polarised at $1300 \mathrm{mV}$ (SCE) show a relatively large peak at frequencies in the range $100 \mathrm{~Hz}-10 \mathrm{~Hz}$ that could indicate the complete deterioration of the protective properties of the oxide film. The large peak might include the contributions of both time constants, which related to charge transfer and the remaining oxide film on the alloy surface.

The EIS results indicate that the oxide layer is increasingly disturbed with the increase in the electric field applied (overpotential) leading to an increasingly less protective oxide layer on the Ti alloy than that formed at OCP.

The EIS plots were interpreted using the $\mathrm{Z}_{\text {view }}$ plot and the equivalent electrical circuits shown in Figure 3. Three different equivalent electric circuits were chosen to represent the electrochemical behavior of the Ti alloy under the various polarisation conditions used. EIS data obtained at OCP were fitted to the equivalent electric circuit shown in Figure 3a, whereas the diagrams corresponding to the specimens polarised at $500 \mathrm{mV}(\mathrm{SCE})$ and $1300 \mathrm{mV}(\mathrm{SCE})$, the equivalent circuits shown in Figures $3 \mathrm{~b}$ and $3 \mathrm{c}$ were used.

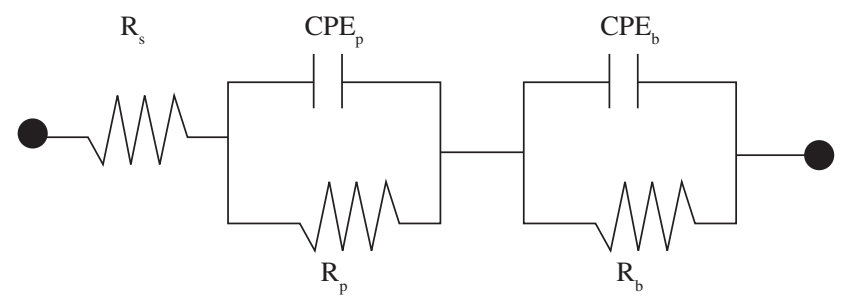

(a)

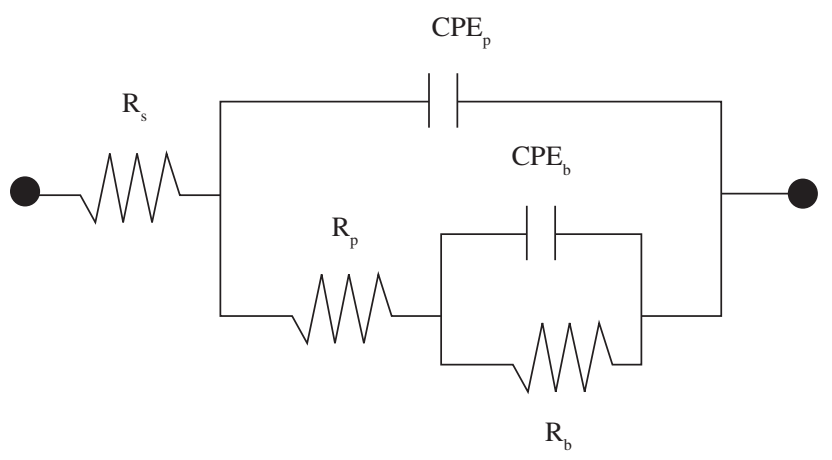

(b)

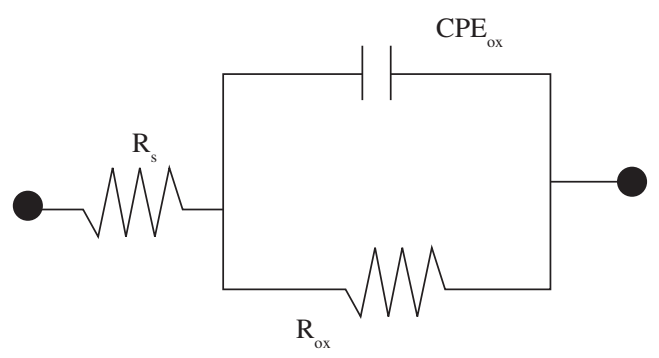

(c)

Figure 3. Equivalent electrical circuit used for fitting experimental data obtained at a) OCP; b) $500 \mathrm{mV}(\mathrm{SCE})$; and c) $1300 \mathrm{mV}(\mathrm{SCE})$, which are shown in Figure 2.
The equivalent electrical circuit shown in Figure 3a was used by Kolman and Scully ${ }^{4,5}$ and Yu et al. ${ }^{9}$ to study oxide films on titanium and titanium alloys in aqueous environments, while that shown in Figure $3 \mathrm{~b}$ was applied by Pan et al. ${ }^{10}$ to investigate the electrochemical behavior of titanium in phosphate buffer solution (PBS). These two circuits are based on the model of a duplex structure oxide composed of an inner barrier layer and an outer porous layer. This latter layer contains microscopic pores, whereas the barrier layer is compact and related to a very large resistance. The two circuits proposed contain resistance and constant phase elements. The components $R_{s}, R_{p}$ and $\mathrm{R}_{\mathrm{b}}$ are related to solution, porous layer and barrier layer resistance, respectively. The constant phase elements, $\mathrm{CPE}_{\mathrm{b}}$ e CPE are associated to the capacitive behavior showed by the barrier and porous layer, respectively. Incorporation of species from the electrolyte occurs through the microscopic pores of the porous layer. This might result in a slight increase in resistance with time. According to literature ${ }^{11,12}$ this layer is associated to the biocompatibility presented by titanium alloys. The time constant at high frequency is related to this layer. The $\mathrm{R}_{\mathrm{p}}$ component is related to the pores resistance to current transfer.

The parallel components $\mathrm{R}_{\mathrm{b}}$ and $\mathrm{CPE}_{\mathrm{b}}$ represent the processes occurring at the barrier layer and this layer has been associated to the high corrosion resistance of the titanium alloys ${ }^{10}$. The $\mathrm{CPE}_{\mathrm{b}}$ component corresponds to the capacitance of the barrier layer that is accountable for the high phase angles at low frequencies. On the other hand, $\mathrm{R}_{\mathrm{b}}$ is related to the barrier layer resistance to species transport and current transfer.

The values of the equivalent circuit components obtained from fitting to the various equivalent circuits proposed are shown in Table 3 . The errors associated to each fitted component were provided by the program.

For specimens polarised at $500 \mathrm{mV}$ (SCE), the EIS diagrams indicated partial deterioration of the passive film and, consequently, the first model proposed was not proper and the one suggested is shown in Figure $3 b$. The values of $\mathrm{R}_{\mathrm{p}}$ and $\mathrm{CPE}_{\mathrm{p}}$ obtained with this model suggest the thickening of the porous layer, indicated by the increase in resistance and decrease of the layer capacitance. The higher phase angles in the high frequency range obtained at $500 \mathrm{mV}(\mathrm{SCE})$ comparatively to OCP supports this hypothesis. On the other hand, the barrier layer also seems to have been affected by polarisation, as it presents lower resistance values in the polarised condition.

Although both circuits $3 \mathrm{a}$ and $3 \mathrm{~b}$ are based on similar oxide film model, the first model is seemingly more appropriate to simulate highly protective oxide films whereas the second type has been usually associated to defective coatings or films.

The equivalent circuit shown in Figure 3c, with only one time constant, was used to fit the results obtained at $1300 \mathrm{mV}$ (SCE). The sample shows a resistive behavior, as indicated in the Bode plots This response point to the deterioration of both barrier and porous layers as the polarisation increased, with the superposition of the two time constants, as indicated by the relatively broad phase angle peak. However dissolution of the oxide layer at the more positive potential cannot be overruled, as the capacity value increases. According to literature ${ }^{13}$, the change of the phase angle peak at medium frequencies to higher frequencies and the decrease in its capacitive behavior are related to the deterioration of the oxide film properties.

It is proposed that the polarisation at $500 \mathrm{mV}(\mathrm{SCE})$ promotes thickening of the porous and barrier layer however, at the same time, it introduces defects in the barrier layer, exposing the metallic substrate. This latter hypothesis is supported by the decrease in resistance and capacitance of the layer for the results obtained at $500 \mathrm{mV}$ (SCE), comparatively to the OCP. Deterioration is enhanced at $1300 \mathrm{mV}(\mathrm{SCE})$. For this potential, the values of the "barrier" layer resistance were of the same order of magnitude of the porous layer 
Table 3. Values of electrical components obtained from fitting the circuits shown in Figure 3 to the experimental results from electrochemical impedance tests for 72 hours immersion in Hanks' solution at $37^{\circ} \mathrm{C}$ of Ti-13Nb-13Zr alloy at three potentials.

\begin{tabular}{|c|c|c|c|c|c|c|}
\hline \multirow[t]{4}{*}{ Circuit element } & \multicolumn{6}{|c|}{ Ti-13Nb-13Zr } \\
\hline & \multicolumn{2}{|c|}{$\mathrm{OCP}$} & \multicolumn{2}{|c|}{$500 \mathrm{mV}(\mathrm{SCE})$} & \multicolumn{2}{|c|}{$1300 \mathrm{mV}(\mathrm{SCE})$} \\
\hline & \multicolumn{2}{|c|}{ Circuit of Figure $3 \mathrm{a}$} & \multicolumn{2}{|c|}{ Circuit of Figure $3 b$} & \multicolumn{2}{|c|}{ Circuit of Figure $3 \mathrm{c}$} \\
\hline & Value & Error $(\%)$ & Value & Error $(\%)$ & Value & Error $(\%)$ \\
\hline $\mathrm{R}_{\mathrm{s}}\left(\Omega \cdot \mathrm{cm}^{2}\right)$ & 92.96 & 0.26 & 94.31 & 0.56 & 91.52 & 0.67 \\
\hline $\mathrm{R}_{\mathrm{p}}\left(\mathrm{K} \Omega \cdot \mathrm{cm}^{2}\right)$ & 22.72 & 6.45 & 52.03 & 7.98 & - & - \\
\hline $\mathrm{CPE}_{\mathrm{p}}\left(\mu \mathrm{F} \cdot \mathrm{cm}^{-2}\right)$ & 126.77 & 1.02 & 6.23 & 1.90 & - & - \\
\hline$\alpha_{\mathrm{p}}$ & 0.73 & \# & 0.93 & 0.27 & - & - \\
\hline $\mathrm{CPE}_{\mathrm{b} / \mathrm{ox}}\left(\mu \mathrm{F} \cdot \mathrm{cm}^{-2}\right)$ & 16.78 & 0.30 & 2.00 & 5.50 & 4.70 & 1.20 \\
\hline$\alpha_{\mathrm{b} / \mathrm{ox}}$ & 0.95 & $\#$ & 0.94 & \# & 0.90 & 0.22 \\
\hline $\mathrm{R}_{\mathrm{b} / \mathrm{ox}}\left(\mathrm{M} \Omega \cdot \mathrm{cm}^{2}\right)$ & 8.99 & 9.58 & 2.34 & 3.25 & 0.03 & 0.70 \\
\hline$\chi^{2}$ & \multicolumn{2}{|c|}{$4.5 \mathrm{E}-4$} & \multicolumn{2}{|c|}{$1.7 \mathrm{E}-3$} & \multicolumn{2}{|c|}{$1.6 \mathrm{E}-3$} \\
\hline
\end{tabular}

\# - Value was fixed.

(resistance) at OCP. This indicates that as the polarisation increases the layer becomes highly defective, exposing the metallic substrate at the pores base.

\section{Conclusions}

The results of this study indicated that polarisation resulted in decreased protective properties of the oxide film on titanium alloys. For large overpotentials (1300 $\mathrm{mV}(\mathrm{SCE})$ ) the barrier layer becomes highly defective, exposing the metallic substrate at the pore bases, causing the decrease in its resistance. Based on the EIS results we suggest that barrier layer deterioration must be the reason for the increase in current always found at potentials around $1300 \mathrm{mV}$ (SCE) in the polarisation curves of Ti and its alloys.

\section{References}

1. Birch JR, Burleigh TD. Oxides formed on titanium by polishing, etching, anodizing, or thermal oxidizing. Corrosion. 2000; 56(12):1233-1241.

2. Cai Z, Nakajima H, Woldu M, Berglund A, Bergman M, Okabe T. In vitro corrosion resistance of titanium made using different fabrication methods. Biomaterials. 1999; 20(2):183-190.

3. Cai Z, Shafer T, Watanabe I, Nunn ME, Okabe T. Electrochemical characterization of cast titanium alloys. Biomaterials. 2003; 24(2):213-218.

4. Kolman DG, Scully JR. Electrochemistry and passivity of Ti-15V-3Cr-3Al$3 \mathrm{Sn} \beta$-titanium alloy in ambient temperature aqueous chloride solutions. Journal of the Electrochemical Society. 1994; 141(10):2633-2641.

5. Kolman DG, Scully JR. Electrochemistry and passivity of a Ti$15 \mathrm{Mo}-3 \mathrm{Nb}-3 \mathrm{Al}$ beta-titanium alloy in ambient temperature aqueous chloride solutions. Journal of the Electrochemical Society. 1993; 140(10):2771-2779.

6. Choubey A, Balasubramaniam R, Basau B. Effect of replacement of V by $\mathrm{Nb}$ and $\mathrm{Fe}$ on the electrochemical and corrosion behavior of Ti-6Al-4V in simulated physiological environment. Journal of Alloys and Compounds. 2004; 381(1/2):288-294.

7. Assis SL. Investigation on the corrosion resistance of Ti-13Nb-13Zr alloy by electrochemical techniques and surface analysis. [Ph.D Thesis]. University of São Paulo, IPEN; Brazil, 2006.

8. Schneider SG. Processing and characterization of Ti-13Nb-13Zr alloy for Biomedical Application. [Ph.D thesis]. University of São Paulo, IPEN; Brazil, 2001.

9. Yu SY, Brodrick CW, Ryan MP, Scully JR. Effects of $\mathrm{Nb}$ and $\mathrm{Zr}$ alloying additions on the activation behavior of $\mathrm{Ti}$ in hydrochloric acid. Journal of the Electrochemical Society. 1999; 146(12):4429-4438.

10. Pan J, Thierry D, Leygraf C. Electrochemical impedance spectroscopy study of the passive oxide film on titanium for implant application. Electrochimica Acta. 1996; 41(7/8):1143-1153.

11. Pan J, Thierry D, Leygraf C. Hydrogen peroxide toward enhanced oxide growth on titanium in PBS solution: Blue coloration and clinical relevance. Journal of Biomedical Materials Research. 1996; 30(3):393-402.

12. Pan J, Liao H, Leygraf C, Thierry D, Li J. Variation of oxide films on titanium induced by osteoblast-like cell culture and the influence of an $\mathrm{H}_{2} \mathrm{O}_{2}$ pretreatment. Journal of Biomedical Materials Research. 1998; $40(2): 244-256$.

13. Palomino LEM. Microstructural characterization and electrochemical impedance spectroscopy study of the corrosion resistance of 2024-T3 alloy, used in the aeronautical industry, coated with an environmental friendly conversion coating. [M.Sc. Dissertation]. University of São Paulo: Brazil; 2004. 